\title{
Capacidade combinatória e efeito recíproco em características agronômicas do feijão
}

\section{Combining ability and reciprocal effect on agronomical traits of bean}

\author{
Joana Neres da Cruz Baldissera ${ }^{1 *}$; Giseli Valentini ${ }^{1}$; \\ Marlon Mathias Dacal Coan²; Carmelice Boff de Almeida'; \\ Altamir Frederico Guidolin ${ }^{4}$ J Jefferson Luís Meirelles Coimbra ${ }^{4}$
}

\section{Resumo}

O objetivo deste trabalho foi avaliar a capacidade geral de combinação dos genitores envolvidos nos cruzamentos e a capacidade específica de combinação dos híbridos, bem como o efeito recíproco em relação as características agronômicas em feijoeiro. Inicialmente foram realizados os cruzamentos dialélicos, intercruzando os seis genitores: Xan 159, Pérola, BAF 63, IPR Uirapuru, BRS Supremo, BRS Valente, gerando trinta e seis combinações. As sementes $F_{1}$ juntamente com os genitores foram levadas a campo em delineamento inteiramente casualizado com duas repetições, sendo que cada planta foi considerada uma unidade de observação, em que ocorre número desigual de plantas nas diferentes combinações híbridas. As plantas foram avaliadas quanto aos seis caracteres (ciclo, estatura de planta, inserção do primeiro legume, diâmetro do caule, número de legumes por planta e número de grãos por legume), sendo posteriormente realizadas as análises estatísticas utilizando o Método I de Griffing. Em relação à capacidade geral de combinação a cultivar Pérola é considerada promissora para o Planalto Catarinense. Com base na capacidade específica as melhores combinações foram Xan 159 x BRS Supremo, Xan 159 x BRS Valente, Pérola x BAF 63, BAF 63 x IPR Uirapuru e BAF 63 x BRS Valente. Os valores para o efeito recíproco também foram significativos indicando que existe a presença de efeito citoplasmático e de genes nucleares do genitor feminino nos caracteres avaliados. O genótipo indicado como um bom genitor feminino e masculino com base no efeito recíproco é o acesso BAF 63, quando se deseja aumentar EST e NLP. A linhagem Xan 159 foi promissora quando utilizada como genitor feminino para incrementar Ciclo, EST, IPL, DC, NLP e NGL. As cultivares BRS Valente e IPR Uirapuru são indicadas como genitores masculinos para proporcionar um aumento do Ciclo, EST, IPL, DC, NLP e NGL.

Palavras-chave: Dialelo desbalanceado, dialell05SAS, Phaseolus vulgaris L

\footnotetext{
Abstract

The objective of this study was to evaluate the general combining ability of parents involved in crosses, and specific combining ability of hybrids, as well as reciprocal effect on six agronomic traits in common

1 Pós-graduandos do curso de Doutorado em Genética e Melhoramento da Universidade Estadual de Maringá, UEM. Av. Colombo, 5.790 Jd. Universitário, CEP 87020-900, Maringá, PR. E-mail: jondcb@gmail.com; valentini_gi@hotmail.com

2 Pós-graduando do curso de Mestrado em Genética e Melhoramento da UEM, Maringá, PR. E- mail: marloncoan@gmail.com

3 Pós-graduando do curso de Mestrado em Produção Vegetal da Universidade do Estado de Santa Catarina, UDESC/CAV. Av. Luiz de Camões, 2090, Bairro Conta Dinheiro, Caixa Postal 281, CEP 88520-000. Lages, SC. E-mail: carmelice_32@hotmail.com

4 Profs. Adjunto do CAV/UDESC, Dept ${ }^{\circ}$ de Agronomia, Instituto de Melhoramento e Genética Molecular da UDESC, IMEGEM. Programa de Pós Graduação em Produção Vegetal. UDESC/CAV, Lages, SC. E-mail: altamirguidolin@gmail.com; coimbrajefferson@cav.udesc.br

* Autor para correspondência
} 
bean: cycle, plant height, first pod insertion, diameter stem, number of pods per plant and number of grains per pod. The experiment was conducted in a greenhouse, where were performe the diallel cross, interbreeding the six parents: Xan 159, Perola, BAF 63, IPR Uirapuru, BRS Supremo, BRS Valente, generating thirty six combinations. The $\mathrm{F}_{1}$ seeds with the parents were taken to the field in a completely randomized design with two repetitions of the thirty-six combinations obtained, totaling seventy-two plot and each plant was considered an observation unit, which is unequal number of plants in different hybrid combinations. The harvested plants were evaluated for six characters, and later performed the statistical analysis using Griffing's Method I. With respect to general combining ability to cultivate Perola is considered promising for the Santa Catarina's plateau. Based on the specific ability the best combinations were Xan 159 x BRS Supremo, Xan 159 x BRS Valente, Perola x BAF 63, BAF 63 x IPR Uirapuru and BAF $63 \times$ BRS Valente. The values for the reciprocal effect was also significant indicating that there is the presence of effect of cytoplasmic and nuclear genes in the female parent traits, The genotype indicated as a good parent females and male based on the reciprocal effect is the access BAF 63, when are wish to increase EST and NLP. The line Xan 159 was promising when used as female parent to increase cycle, EST, IPL, DC, NLP and NGL. The cultivars BRS Valente and IPR Uirapuru are identified as male parents to provide an increase in the cycle, EST, IPL, DC, NLP and NGL.

Key words: Unbalanced diallel, dialell05SAS, Phaseolus vulgaris L

\section{Introdução}

O feijão, cultivado em todo território, brasileiro e é um dos produtos agrícolas de maior importância econômico-social, devido principalmente à mãode-obra empregada durante o ciclo da cultura, por ser cultivado por pequenos, médios e grandes agricultores e por fazer parte da dieta da maioria da população brasileira (WANDER, 2005).

Frente às tendências atuais de crescimento da população e do aumento no consumo do feijão é previsto uma demanda crescente do mesmo, a qual só poderá ser suprida se novas cultivares forem desenvolvidas, através da melhoria do ambiente de produção ou pela incorporação de novas áreas ainda não utilizadas para a agricultura (ELIAS, 2006).

O melhoramento genético de plantas possui as ferramentas necessárias para a criação de novas cultivares de feijão com características agronômicas desejáveis. Dentre estas ferramentas se destaca a seleção e o uso de cruzamentos artificiais, que recombinam a variabilidade genética presente desenvolvendo cultivares melhoradas (BERNARDO; BOHN, 2007). Os cruzamentos dialélicos são esquemas frequentemente utilizados no melhoramento genético, em que são intercruzados $n$ genitores dois a dois, produzindo $n^{2}$ combinações. Por meio dos cruzamentos dialélicos é possível conhecer o controle genético dos caracteres, o que auxilia na condução e na seleção das populações segregantes (VENCOVSKY; BARRIGA, 1992). O dialelo também fornece ao melhorista informações em relação ao comportamento dos genitores entre si e suas combinações híbridas.

A partir dos cruzamentos dialélicos é possível estimar a capacidade geral de combinação (CGC) e a capacidade específica de combinação (CEC). A CGC é atribuída a efeitos aditivos sendo que é importante o seu conhecimento em programas de melhoramento para a indicação e seleção de genitores (MAKANDA et al., 2010). A CEC está relacionada aos efeitos gênicos não-aditivos, que caracteriza a diferença das combinações híbridas em relação ao comportamento médio dos genitores (FERREIRA et al., 2002), o que contribui para a indicação da melhor combinação híbrida.

Além desses dois parâmetros uma informação importante esta inserida nos cruzamentos recíprocos dos híbridos (REC), que indica qual o genótipo pode ser utilizado como genitor masculino ou como genitor feminino em uma combinação híbrida, de acordo com o seu desempenho como doador ou como receptor de pólen. O efeito REC é dividido em efeito materno quando os genes são provenientes do núcleo do genitor utilizado como mãe e efeito extracromossômico quando os genes 
são provenientes da mitocôndria e dos cloroplastos (RAMALHO; SANTOS; PINTO, 2008).

A metodologia (método I) desenvolvida por Griffing (1956) que permite estimar a CGC, CEC e o efeito REC é considerado importante, pois corresponde à avaliação das $\mathrm{n}^{2}$ combinações (genitores, híbridos e recíprocos) obtidas nos cruzamentos, sendo possível detectar variações genéticas a partir do comportamento do híbrido $\mathrm{F}_{1} \mathrm{e}$ do seu recíproco (GRIFFING, 1956).

Segundo Silva et al. (2000), todas as metodologias de análise dialélica já disponíveis pressupõem a homogeneidade e a independência dos erros relativos às médias, exceto a que trata dos dialelos desbalanceados de Cruz, Regazzi e Carneiro (2004), que contempla a heterocedasticidade das médias, advinda de número desigual de observações das diferentes combinações híbridas, avaliadas em delineamento experimental inteiramente casualizado.

Este trabalho teve por objetivo estimar a capacidade geral de combinação dos genitores utilizados nos cruzamentos, a capacidade específica de combinação dos híbridos $\mathrm{F}_{1}$ bem como o efeito dos recíprocos em um dialelo desbalanceado para seis caracteres agronômicos em feijoeiro: ciclo, estatura de planta (EST), inserção do primeiro legume (IPL), diâmetro do caule (DC), número de legumes por planta (NLP), e número de grãos por legume (NGL).

\section{Material e Métodos}

Para a realização do experimento foram escolhidos seis genótipos de feijão contrastantes para as caracteríticas agronômicas em questão. Os genótipos são: Xan 159, Pérola, BAF 63, IPR Uirapuru, BRS Supremo e BRS Valente, os quais foram semeados em casa de vegetação. Após a emergência dos botões florais foram realizados os cruzamentos artificiais, de todos os genótipos entre si de acordo com Vieira (1967), com o objetivo de obter as sementes $F_{1}$ que foram semeados a campo juntamente com os seus genitores no ano agrícola 2009/2010.

As parcelas experimentais foram semeadas manualmente com 15 sementes por metro linear, em parcelas constituídas por três fileiras de $1 \mathrm{~m}$ de comprimento espaçadas com $0,5 \mathrm{~m}$ entre si, totalizando uma área total de $1,5 \mathrm{~m}^{2}$ por parcela e uma área útil de $0,4 \mathrm{~m}^{2}$ constituída pela linha central, utilizando como efeito de bordadura as linhas das extremidades com os genitores que originaram os respectivos híbridos.

$\mathrm{O}$ experimento foi conduzido em delineamento inteiramente casualizado com duas repetições das trinta e seis combinações obtidas, sendo que cada planta foi considerada uma unidade de observação, em que ocorre número desigual de plantas nas diferentes combinações híbridas.

Para a avaliação de ciclo foi considerado o número de dias transcorridos da emergência à maturação, sendo está avaliada após o estágio fenológico de maturação fisiológica (R9) em que $50 \%+1$ das plantas da parcelas apresentam perda de pigmentação nas vagens ficando secas e as sementes apresentam coloração típica da cultivar (CIAT, 1982). Após a colheita do experimento todas as plantas do dialelo foram avaliadas de acordo com os cinco caracteres: estatura de planta (EST) medida em centímetros da cicatriz cotiledonar até o final da haste principal, inserção do primeiro legume (IPL) medida em centímetros da cicatriz cotiledonar até a inserção do primeiro legume, diâmetro do caule (DC) medido em milímetros na cicatriz cotiledonar, número de legumes por planta (NLP) e número de grãos por legumes (NGL) (IPGRI, 2001).

Os dados obtidos foram submetidos a análises estatísticas considerando os efeitos fixos, utilizando o pacote Diallel-SAS05 do programa SAS (ZHANG; KANG; LAMKEY, 2005). Foi realizada uma análise dialélica, seguindo o modelo 1 método I de Griffing (1956) que estima a capacidade geral de combinação (CGC), a capacidade específica de combinação (CEC) e o efeito recíproco (REC) a partir dos genitores, híbridos $F_{1}$ e híbridos $F_{1}$ 
recíprocos obtidos nos cruzamento. Para verificar se as estimativas diferiram de zero, foi realizado o teste $\mathrm{t}$ de Student (ZHANG; KANG; LAMKEY, 2005) em nível de $5 \%$ de significância.

O modelo estatístico proposto por Griffing (1956) decompõe a média $C_{i j}$ da combinação híbrida $(i \neq j)$ ou do progenitor $(i=j)$ nos seguintes efeitos:

$$
C_{i j}=m+\hat{g}_{i}+\hat{g}_{j}+\hat{S}_{i j}+r_{i j}+\hat{e}_{i j}
$$

em que:

$m$ : efeito médio de todos os tratamentos; $\hat{g}_{i}$ : efeito da capacidade geral de combinação do pai $i$, e corresponde ao desvio do seu desempenho médio em combinações híbridas; $\hat{g}_{j:}$ efeito da capacidade geral de combinação do pai de ordem $j ; \hat{S}_{i j \text { : }}$ efeito da capacidade específica de combinação do cruzamento $C_{i j}$ e significa que seu desempenho e superior ou inferior em relação ao esperado com base no comportamento médio dos pais envolvidos; $r_{i j:}$ efeito da capacidade específica de combinação manifestada no cruzamento recíproco, envolvendo os pais $i$ e $j ; \hat{e}_{i j}$ erro experimental médio associado às médias da tabela dialélica.

De acordo com Cruz, Regazzi e Carneiro (2004), a solução do modelo 1 método I de Griffing (1956) com o dialelo desbalanceado, em que as médias são estimadas com número desigual de observações das diferentes combinações híbridas, passa a ser pelo método dos mínimos quadrados ponderados.

\section{Resultados e Discussão}

Os valores do quadrado médio do tratamento foram significativos a $5 \%$ pelo teste $\mathrm{F}$ para todas as características avaliadas (Tabela 1), indicando que existe diferença genética entre as trinta e seis combinações. Isso comprova que os genótipos escolhidos são contrastantes entre si, o que é importante para o sucesso em um programa de melhoramento, pois assim, a variabilidade genética é ampliada favorecendo a seleção (RAMALHO; SANTOS; PINTO, 2008).
O efeito da CGC foi significativo (Tabela 1), indicando a presença de efeito aditivo nas características exceto para NLP. Já para a CEC o quadrado médio foi significativo para todas as características, demonstrando a existência de efeitos não aditivos influenciando nos seis caracteres avaliados. Segundo Cruz, Sediyama e Sediyama (1987) é a partir da existência dos efeitos aditivos e não aditivos que reside a viabilidade e o sucesso dos programas de melhoramento.

O coeficiente de variação $(\mathrm{CV})$ estimado, foi alto para EST, IPL, DC, NLP e NGL, demonstrando que estas características são afetadas por variações ambientais. Conforme Veiga, Ferreira e Ramalho (2000) isto indica baixa precisão experimental, sendo que a herdabilidade a ser obtida será pequena, nessa condição em que os híbridos foram avaliados. Segundo Nóbrega et al. (2010), em dialelos de várias culturas são relatados os CV's de magnitude média a alta para caracteres relacionados a produtividade de grãos, pois estas são características poligênicas (RAMALHO; SANTOS; PINTO, 2008).

Para o efeito recíproco apenas NGL não apresentou efeito significativo. Desta forma se admite que o efeito citoplasmático e os genes nucleares do genótipo utilizado como mãe estão influenciando as outras cinco características (ciclo, EST, IPL, DC e NLP). De acordo com Ramalho, Santos e Pinto (2008) se a herança de um caráter é controlada por genes nucleares, os resultados dos cruzamentos deveriam ser iguais ao seu recíproco, porém se eles são diferentes é devido aos efeitos citoplasmáticos e aos genes nucleares do genitor feminino.

Com relação a CGC (Tabela 2) o genótipo Xan 159 apresentou valores negativos e significativos a $5 \%$ pelo teste $\mathrm{t}$, o que indica que ele contribui para a diminuição das seis características avaliadas. Em contrapartida a cultivar Pérola apresentou valores significativos e positivos para ciclo, EST, IPL e DC, podendo então ser indicada para blocos de cruzamentos em que se deseja o incremento dessas características. 
Tabela 1. Análise dialélica pelo método I de Griffing (1956) para os seis caracteres: ciclo, estatura de planta (EST), altura de inserção do primeiro legume (IPL), diâmetro do caule (DC), número de legumes por planta (NLP) e número de grãos por legume (NGL) em feijão, especificando os efeitos de capacidade geral (CGC) e específica de combinação (CEC) e efeito recíproco (REC).

\begin{tabular}{lccccccc}
\hline \multirow{2}{*}{ F.V. } & \multirow{2}{*}{ GL } & \multicolumn{7}{c}{ Quadrado Médio $^{(1)}$} \\
\cline { 3 - 8 } & & Ciclo & EST & IPL & DC & NLP & NGL \\
\hline \multirow{2}{*}{ Tratamento } & & Dias & $\mathrm{cm}$ & $\mathrm{Cm}$ & $\mathrm{mm}$ & & \\
CGC & $55)$ & $215,3^{*}$ & $7690,6^{*}$ & $218,9^{*}$ & $16,6^{*}$ & $360,6^{*}$ & $7,3^{*}$ \\
CEC & $508,8^{*}$ & $23628,6^{*}$ & $667,2^{*}$ & $35,0^{*}$ &. & $114,6^{\text {ns }}$ & $30,6^{*}$ \\
REC & 15 & $198,9^{*}$ & $5408,8^{*}$ & $136,3^{*}$ & $15,4^{*}$ & $554,0^{*}$ & $3,3^{*}$ \\
\hline Resíduo & 15 & $136,1^{*}$ & $2268,5^{*}$ & $95,5^{*}$ & $7,1^{*}$ & $256,1^{*}$ & $1,8^{\text {ns }}$ \\
\hline CV $^{(2)}(\%)$ & 391 & 7,0 & 557,9 & 26,2 & 2,4 & 94,5 & 0,8 \\
\hline Média Geral & & 2,57 & 38,61 & 38,86 & 27,71 & 60,57 & 21.69 \\
\hline
\end{tabular}

(1) *: efeito significativo a 5\% pelo teste $\mathrm{F}$; ns: efeito não significativo pelo teste $\mathrm{F}$.

(2) $\mathrm{CV}(\%)$ : coeficiente de variação.

Fonte: Elaboração dos autores.

Tabela 2. Estimativas da capacidade geral de combinação $\left(\hat{g}_{i}\right)$ em feijão para os seis caracteres: ciclo, estatura de planta (EST), altura de inserção do primeiro legume (IPL), diâmetro do caule (DC), número de legumes por planta (NLP) e número de grãos por legume (NGL) para os seis genitores utilizados no cruzamento dialélico.

\begin{tabular}{lcccccc}
\hline \multicolumn{1}{c}{ Genitores } & \multicolumn{7}{c}{$\hat{g}_{i}$} \\
\hline & Ciclo & EST & IPL & DC & NLP & NGL \\
\hline Xan 159 & dias & cm & $\mathrm{cm}$ & $\mathrm{mm}$ & & \\
Pérola & $-0,9^{*}$ & $-13,8^{*}$ & $-2,5^{*}$ & $-0,8^{*}$ & $-1,7^{\text {ns }}$ & $-0,6^{*}$ \\
BAF 63 & $2,3^{*}$ & $23,4^{*}$ & $4,0^{*}$ & $0,7^{*}$ & $0,2^{\text {ns }}$ & $0,2^{\text {ns }}$ \\
IPR Uirapuru & $1,5^{*}$ & $-8,0^{*}$ & $-0,2^{\text {ns }}$ & $-0,3^{\text {ns }}$ & $-0,5^{\text {ns }}$ & $0,5^{*}$ \\
BRS Supremo & $0,7^{*}$ & $-5,3^{*}$ & $-1,5^{*}$ & $0,3^{\text {ns }}$ & $0,9^{\text {ns }}$ & $0,4^{*}$ \\
BRS Valente & $-1,9^{*}$ & $-4,5^{\text {ns }}$ & $-0,1^{\text {ns }}$ & $0,0^{\text {ns }}$ & $0,5^{\text {ns }}$ & $0,2^{*}$ \\
\hline
\end{tabular}

*Significativo a $5 \%$ de probabilidade pelo teste $\mathrm{t}$; ns: efeito não significativo pelo teste $\mathrm{F}$.

Fonte: Elaboração dos autores.

Foi evidenciado que o acesso BAF 63 e as cultivares IPR Uirapuru, BRS Supremo e BRS Valente apresentaram valores positivos e significativos para NGL contribuindo para o aumento deste componente do rendimento. A cultivar IPR Uirapuru se destaca apresentando em média quatro grãos a mais por legume (Tabela 2). Segundo Paini et al. (1996) estimativas da CGC (positivas ou negativas) tem sido de grande valia para a seleção de genitores em programas de melhoramento, pois as altas estimativas de $g_{i}$ ocorrem geralmente em genótipos com maior frequência de alelos favoráveis e isso possibilitará maior facilidade na seleção de populações segregantes (BENIN et al., 2009).

Já as estimativas de CEC, julgadas a partir das médias dos genitores utilizados nos cruzamentos (SALEEM; MIRZA; HAQ, 2010), são importantes para informar qual as melhores combinações híbridas. O ideal é que estas apresentem altas estimativas para $s_{i j}$ e envolvam pelo menos um genitor que tenha uma alta CGC.

As combinações híbridas que aumentaram o ciclo da planta foram Xan 159 x BRS Supremo, 
Pérola x Baf 63, Baf 63 x IPR Uirapuru e Baf 63 $x$ BRS Valente e as que diminuíram o ciclo foram Xan 159 x BRS Valente, Pérola x IPR Uirapuru, Pérola x BRS Supremo, Pérola x BRS Valente e IPR Uirapuru x BRS Supremo (Tabela 3). Os híbridos que diminuem o ciclo podem ser utilizados no desenvolvimento de cultivares para o Planalto Serrano onde há impossibilidade de serem feitas duas safras de feijão por ano em decorrência das baixas temperaturas no final do ciclo, a qual pode limitar o produtividade de grãos (BISOGNIN et al., 1997). Um genótipo com ciclo mais longo terá mais tempo (em dias) para utilizar as altas temperaturas nos meses de dezembro a fevereiro para encher os grãos, favorecendo assim a produtividade de grãos que não seria menor quando comparada com os locais onde pode se fazer duas safras (safra e safrinha).

Para a característica estatura de planta (EST) as combinações que contribuem para a diminuição da mesma foram: Xan 159 x Baf 63, Pérola x IPR Uirapuru e Pérola $x$ BRS Valente e as que contribuem para um aumento foram Xan 159 x BRS Supremo, Xan 159 x BRS Valente, Pérola x Baf 63, Baf 63 x IPR Uirapuru e Baf 63 x BRS Valente.

A altura das plantas é correlacionada com o pontecial produtivo da maioria das culturas (WU et al., 2010) e de acordo com Souza et al. (2009) também está relacionada com a IPL, ou seja quando a EST aumenta ou diminui a IPL é afetada como pode ser observado nas combinações Pérola $\mathrm{x}$ IPR Uirapuru (EST -11,8 cm e IPL $-3,0 \mathrm{~cm}$ ) e Pérola x BRS Valente (EST -27,2 e IPL -9,6) que apresentaram valores negativos e significativos. Uma planta com IPL mais alta, facilita a colheita mecânica e diminui a contaminação dos legumes, pois evita o contato entre legume e solo podendo aumentar a produtividade de grãos (Tabela 3).

Os cruzamentos mais promissores para aumentar a característica diâmetro do caule (DC) foram Xan 159 x IPR Uirapuru e Xan 159 x BRS Supremo.
A combinação IPR Uirapuru $\mathrm{x}$ BRS Valente apresentou uma redução no DC (Tabela 3). Este caráter é de extrema importância para a planta, pois ele dá a ela suporte. As plantas que possuem um DC muito fino tendem ao acamamento e este dificulta a colheita mecânica e diminui a produtividade de grãos (ZANATTA; OERLECKE, 1991). Segundo Adams (1973) plantas com caules mais grossos são mais resistentes ao acamamento. Esta característica é influenciada pelo ambiente e por fatores estruturais e mecânicos das plantas (HALL; SPOSARO; CHIMENTI, 2010).

As combinações híbridas Xan 159 x BRS Valente, Pérola x Baf 63, Pérola x BRS Valente, Baf 63 x IPR Uirapuru, Baf 63 x BRS Valente e IPR Uirapuru $x$ BRS Supremo contribuem para dois dos componentes da produtividade de grãos, já que apresentaram valores positivos e significativos para pelo menos um dos componentes do rendimento NLP e NGL (Tabela 3).

Os efeitos dos recíprocos (REC) informam qual o genótipo é o mais promissor quando utilizado como genitor feminino ou masculino para as seis características de interesse agronômico. Sendo assim, quando se deseja aumentar o ciclo da planta deve ser utilizada a combinação IPR Uirapuru x Baf 63, sendo o IPR Uirapuru o genitor feminino (Tabela 4). Nesta combinação houve aumento aproximado de oito dias no ciclo. Quando se deseja uma planta com um ciclo mais curto podem ser utilizadas as combinações BRS Valente x Baf 63 e BRS Valente $\mathrm{x}$ BRS Supremo, tendo como genitor feminino a cultivar BRS Valente.

Para as características que compreendem a arquitetura de planta (EST, IPL e DC) os cruzamentos recíprocos Pérola x Xan 159 e BRS Valente $\mathrm{x}$ IPR Uirapuru demonstram que os melhores genótipos utilizados como genitores femininos são Pérola e BRS Valente, quando o objetivo é diminuir estas características. Quando o objetivo é aumentá-la pode ser utilizado como 
genitor feminino o IPR Uirapuru, nas combinações IPR Uirapuru x Xan 159 e IPR Uirapuru x Pérola. Para os caracteres de produtividade de grão (NLP e NGL) apenas a combinação Baf 63 vs. IPR Uirapuru apresentou valor positivo, as demais combinações não apresentaram ação do efeito recíproco. Este cruzamento indica que o melhor genitor masculino é o Baf 63 e o feminino é o IPR Uirapuru.

Tabela 3. Estimativas dos efeitos da capacidade específica de combinação $\left(\hat{S}_{i j}\right)$ em feijão para os seis caracteres avaliados: ciclo, estatura de planta (EST), altura de inserção do primeiro legume (IPL), diâmetro do caule (DC), número de legumes por planta (NLP) e número de grãos por legume (NGL) para todas as combinações possíveis nos cruzamentos dialélicos realizados.

\begin{tabular}{|c|c|c|c|c|c|c|c|}
\hline \multicolumn{2}{|c|}{ Genitores } & \multicolumn{6}{|c|}{$\hat{S}_{i j}$} \\
\hline$I$ & $J$ & Ciclo & EST & IPL & $\mathrm{DC}$ & NLP & NGL \\
\hline & & dias & $\mathrm{cm}$ & $\mathrm{cm}$ & $\mathrm{mm}$ & & \\
\hline Xan 159 & Pérola & $-1,4^{\mathrm{ns}}$ & $-4,3^{\mathrm{ns}}$ & $-2,5^{\mathrm{ns}}$ & $-0,7^{\text {ns }}$ & $-1,1^{\mathrm{ns}}$ & $-0,2^{\mathrm{ns}}$ \\
\hline Xan 159 & BAF 63 & $-0,6^{\text {ns }}$ & $-22,5^{*}$ & $-2,2^{\mathrm{ns}}$ & $-0,4^{\text {ns }}$ & $-2,6^{\mathrm{ns}}$ & $0,2^{\text {ns }}$ \\
\hline Xan 159 & IPR Uirapuru & $0,1^{\text {ns }}$ & $7,1^{\mathrm{ns}}$ & $2,6^{*}$ & $1,2 *$ & $1,4^{\mathrm{ns}}$ & $-0,3^{\text {ns }}$ \\
\hline Xan 159 & BRS Supremo & $2,8^{*}$ & $17,5^{*}$ & $1,9^{\text {ns }}$ & $1,1^{*}$ & $6,1^{\text {ns }}$ & $0,6^{\mathrm{ns}}$ \\
\hline Xan 159 & BRS Valente & $-4,6^{*}$ & $48,6^{*}$ & $4,4^{\mathrm{ns}}$ & $0,7^{\mathrm{ns}}$ & $11,5^{*}$ & $0,9^{*}$ \\
\hline Pérola & BAF 63 & $3,3^{*}$ & $17,1^{*}$ & $1,2^{\mathrm{ns}}$ & $0,0^{\mathrm{ns}}$ & $2,8^{\mathrm{ns}}$ & $0,5^{*}$ \\
\hline Pérola & IPR Uirapuru & $-3,1^{*}$ & $-11,8^{*}$ & $-3,0 *$ & $0,0^{\text {ns }}$ & $-1,4^{\mathrm{ns}}$ & $0,3^{\text {ns }}$ \\
\hline Pérola & BRS Supremo & $-0,4$ & $-5,7^{\mathrm{ns}}$ & $-1,1^{\text {ns }}$ & $-0,2^{\text {ns }}$ & $1,3^{\text {ns }}$ & $0,1^{\text {ns }}$ \\
\hline Pérola & BRS Valente & $-3,2 *$ & $-27,2 *$ & $-9,7 *$ & $0,9^{\text {ns }}$ & $8,8^{\mathrm{ns}}$ & $1,3^{*}$ \\
\hline BAF 63 & IPR Uirapuru & $6,2^{*}$ & $13,9^{*}$ & $0,5^{\mathrm{ns}}$ & $0,7^{\mathrm{ns}}$ & $8,9^{*}$ & $-0,2^{\mathrm{ns}}$ \\
\hline BAF 63 & BRS Supremo & $-0,7^{\mathrm{ns}}$ & $4,2^{\mathrm{ns}}$ & $1,5^{\mathrm{ns}}$ & $1,0^{\mathrm{ns}}$ & $2,3^{\text {ns }}$ & $-0,5^{\text {ns }}$ \\
\hline BAF 63 & BRS Valente & $4,2^{*}$ & $45^{*}$ & $3,9^{\text {ns }}$ & $1,4^{\mathrm{ns}}$ & $11,8^{*}$ & $0,0^{\mathrm{ns}}$ \\
\hline IPR Uirapuru & BRS Supremo & $-2,5^{*}$ & $-1,7^{\mathrm{ns}}$ & $0,1^{\text {ns }}$ & $-0,5^{\text {ns }}$ & $-4,6^{*}$ & $0,3^{\text {ns }}$ \\
\hline IPR Uirapuru & BRS Valente & $2,4^{\mathrm{ns}}$ & $11,0^{\text {ns }}$ & $3,5^{\text {ns }}$ & $-0,9 *$ & $7,5^{\text {ns }}$ & $-0,2^{\mathrm{ns}}$ \\
\hline BRS Supremo & BRS Valente & $2,2^{\text {ns }}$ & $-7,8^{\text {ns }}$ & $2,6^{\text {ns }}$ & $0,4^{\mathrm{ns}}$ & $-4,4^{\mathrm{ns}}$ & $0,4^{\text {ns }}$ \\
\hline
\end{tabular}

*Significativo a $5 \%$ de probabilidade pelo teste $\mathrm{t}$; ns: efeito não significativo pelo teste $\mathrm{F}$.

$i$ : genitor feminino; $j$ : genitor masculino.

Fonte: Elaboração dos autores.

Tabela 4. Estimativas dos efeitos dos recíprocos $\left(r_{i j}\right)$ para os seis caracteres: ciclo, estatura de planta (EST), altura de inserção do primeiro legume (IPL), diâmetro do caule (DC), número de legumes por planta (NLP) e número de grãos por legume (NGL) para as trinta combinações possíveis nos cruzamentos dialélicos de feijão (Phaseolus vulgaris L.).

\begin{tabular}{|c|c|c|c|c|c|c|c|}
\hline \multicolumn{2}{|c|}{ Genitores } & \multicolumn{6}{|c|}{$r_{i i}$} \\
\hline$J$ & $i$ & Ciclo & EST & IPL & $\mathrm{DC}$ & NLP & NGL \\
\hline & & dias & $\mathrm{Cm}$ & $\mathrm{cm}$ & $\mathrm{mm}$ & & \\
\hline Xan 159 & Pérola & $0,0^{\mathrm{ns}}$ & $-52,1^{*}$ & $-6,2 *$ & $-1,4^{\mathrm{ns}}$ & $-4,1^{\mathrm{ns}}$ & $-0,5^{\text {ns }}$ \\
\hline Xan 159 & BAF 63 & $0,0^{\mathrm{ns}}$ & $-1,9^{\text {ns }}$ & $-0,5^{\mathrm{ns}}$ & $-0,4^{\text {ns }}$ & $-5,1^{\text {ns }}$ & $-0,2^{\text {ns }}$ \\
\hline Xan 159 & IPR Uirapuru & $0,0^{\mathrm{ns}}$ & $7,3^{\mathrm{ns}}$ & $2,8^{*}$ & $0,6^{\mathrm{ns}}$ & $4,8^{\mathrm{ns}}$ & $-0,2^{\text {ns }}$ \\
\hline Xan 159 & BRS Supremo & $0,0^{\mathrm{ns}}$ & $5,0^{\text {ns }}$ & $2,6^{\mathrm{ns}}$ & $0,2^{\text {ns }}$ & $3,4^{\text {ns }}$ & $-0,4^{\mathrm{ns}}$ \\
\hline Xan 159 & BRS Valente & $1,7^{*}$ & $-10,1^{\mathrm{ns}}$ & $-0,1^{\mathrm{ns}}$ & $0,3^{\mathrm{ns}}$ & $-1,4^{\mathrm{ns}}$ & $-0,3 *$ \\
\hline Pérola & BAF 63 & $0,1^{\mathrm{ns}}$ & $9,3^{\text {ns }}$ & $-1,2^{\mathrm{ns}}$ & $-0,0^{\text {ns }}$ & $2,8^{\text {ns }}$ & $-0,3 *$ \\
\hline Pérola & IPR Uirapuru & $0,0^{\mathrm{ns}}$ & $0,2^{\text {ns }}$ & $4,0 *$ & $0,6^{\mathrm{ns}}$ & $-0,4^{\mathrm{ns}}$ & $0,2^{\text {ns }}$ \\
\hline Pérola & BRS Supremo & $0,0^{\text {ns }}$ & $-2,8^{\mathrm{ns}}$ & $-1,2^{\mathrm{ns}}$ & $0,3^{\text {ns }}$ & $-1,6^{\mathrm{ns}}$ & $0,1^{\mathrm{ns}}$ \\
\hline
\end{tabular}


continuação

\begin{tabular}{llcccccc} 
Pérola & BRS Valente & $0,0^{\mathrm{ns}}$ & $7,2^{\mathrm{ns}}$ & $-0,3^{\mathrm{ns}}$ & $-0,1^{\mathrm{ns}}$ & $-4,5^{\mathrm{ns}}$ & $-0,4^{*}$ \\
BAF 63 & IPR Uirapuru & $8,5^{*}$ & $3,2^{\mathrm{ns}}$ & $-1,7^{\mathrm{ns}}$ & $-0,2^{\mathrm{ns}}$ & $7,0^{*}$ & $-0,4^{\mathrm{ns}}$ \\
BAF 63 & BRS Supremo & $-1,2^{\mathrm{ns}}$ & $-4,7^{\mathrm{ns}}$ & $0,1^{\mathrm{ns}}$ & $0,0^{\mathrm{ns}}$ & $2,7^{\mathrm{ns}}$ & $-0,1^{\mathrm{ns}}$ \\
BAF 63 & BRS Valente & $-2,1^{*}$ & $1,2^{\mathrm{ns}}$ & $2,5^{\mathrm{ns}}$ & $-0,1^{\mathrm{ns}}$ & $-1,0^{\mathrm{ns}}$ & $0,2^{\mathrm{ns}}$ \\
IPR Uirapuru & BRS Supremo & $-0,4^{\mathrm{ns}}$ & $-0,3^{\mathrm{ns}}$ & $-0,3^{\mathrm{ns}}$ & $-0,2^{\mathrm{ns}}$ & $-0,1^{\mathrm{ns}}$ & $-0,3^{\mathrm{ns}}$ \\
IPR Uirapuru & BRS Valente & $0,0^{\mathrm{ns}}$ & $-9,1^{\mathrm{ns}}$ & $-0,3^{\mathrm{ns}}$ & $-1,6^{*}$ & $-3,4^{\mathrm{ns}}$ & $-0,1^{\mathrm{ns}}$ \\
BRS Supremo & BRS Valente & $-2,0^{*}$ & $7,3^{\mathrm{ns}}$ & $1,2^{\mathrm{ns}}$ & $0,2^{\mathrm{ns}}$ & $2,4^{\mathrm{ns}}$ & $-0,3^{\mathrm{ns}}$ \\
\hline
\end{tabular}

* Significativo a $5 \%$ de probabilidade pelo teste $\mathrm{t}$; ns: efeito não significativo pelo teste $\mathrm{F}$. $i$ : genitor feminino; $j$ : genitor masculino.

Fonte: Elaboração dos autores.

\section{Conclusões}

O estudo do controle genético para as seis características de interesse agronômico para o feijão indica a influencia dos efeitos aditivos e não aditivos sobre essas características, sendo que os efeitos aditivos são superiores.

Acultivar Pérola apresentou a melhor capacidade geral de combinação para as características ciclo, estatura de planta, diâmetro do caule e inserção do primeiro legume em relação aos demais genótipos testados.

Para os cruzamentos realizados existem combinações híbridas favoráveis para pelo menos uma das características avaliadas com base na capacidade específica de combinação.

As avaliações do efeito recíproco confirmam que há diferença quando um genótipo é utilizado como doador ou receptor de pólen, pois existe a presença de efeito citoplasmático e de genes nucleares do genitor feminino nos caracteres avaliados.

\section{Agradecimentos}

Agradecemos à Universidade do Estado de Santa Catarina - UDESC, ao Conselho Nacional de Desenvolvimento Científico e Tecnológico CNPq e à Fundação de Apoio a Pesquisa Científica e Tecnológica do Estado de Santa Catarina FAPESC pela concessão de bolsa e apoio financeiro no desenvolvimento deste trabalho.

\section{Referências}

ADAMS, M. W. Plant architecture and physiological efficiency in the field bean. In: WALL, D. Potentials of field beans and other legumes in Latin America. Cali: CIAT, 1973. p. 266-278.

BENIN, G.; SILVA, G. O.; PAGLIOSA, E. S.; LEMES, C.; SIGNORINI, A.; BECHE, E.; CAPELIN, M. A. Capacidade de combinação em genótipos de trigo estimada por meio de análise multivariada. Pesquisa Agropecuária Brasileira, Brasília, v. 44, n. 9, p. 11451151, 2009.

BERNARDO, R.; BOHN, M. O. Plant breeding in times of change. Crop Science Society of America, Madison, v. 47, n. 3, p. 2-3, 2007.

BISOGNIN, D. A.; ALMEIDA, M. L.; GUIDOLIN, A. F.; NASCIMENTO, J. A. Desempenho de cultivares de feijão em semeadura tardia no planalto catarinense. Ciência Rural, Santa Maria, v. 27, n. 2, p. 193-199, 1997.

CENTRO INTERNACIONAL DE AGRICULTURA TROPICAL - CIAT. Etapas de desarrollo de la planta de fríjol común. Cali: CIAT 1982. 26 p. (Guía de estudio).

CRUZ, C. D.; REGAZZI, A. J.; CARNEIRO, P. C. S. Modelos biométricos aplicados ao melhoramento genético. 3. ed. Viçosa: UFV, 2004. v. 1, 480 p.

CRUZ, C. D.; SEDIYAMA, C. S.; SEDIYAMA, T. Capacidade combinatória e efeitos recíprocos de alguns caracteres em soja (Glycine Max (L) Merrill). Revista Ceres, Viçosa, v. 34, n. 192, p. 432-439, 1987.

ELIAS, T. H. Caracterização da variabilidade genética em germoplasma tradicional de Phaseolus vulgaris $L$. coletado em Santa Catarina. 2006. Tese (Doutorado em Agronomia) - Faculdade de Agronomia. Universidade Estadual de Maringá, Maringá. 
FERREIRA, M. A. J. F.; BRAZ, L. T.; QUEIROZ, M. A.; CHURATA-MASCA, M. G. C.; VENCOVSKY, R. Capacidade de combinação em sete populações de melancia. Revista Pesquisa Agropecuária Brasileira, Brasília, v. 37, n. 7, p. 963-970, 2002.

GRIFFING, B. Concept of general and specific ability in relation to diallel crossing systems. Australian Journal of Biological Sciences, East Melbourne, v. 9, n. 4, p. 46293, 1956.

HALL, A. J.; SPOSARO, M. M.; CHIMENTI, C. A. Stem lodging in sunflower: variations in stem failure moment of force and structure across crop population densities and post-anthesis developmental stages in two genotypes of contrasting susceptibility to lodging. Field Crops Research, Amsterdam, v. 116, n. 1-2, p. 46-51, 2010.

IPGRI. Descritores para Phaseolus vulgaris. Rome: International Plant Genetic Resources Institute, 2001. 45 p.

MAKANDA, I.; TONGOONA, P.; DERERA, J.; SIBIYA, J.; FATO, P. Combining ability and cultivar superiority of sorghum germplasm for grain yield across tropical low- and mid-altitude environments. Field Crops Research, Amsterdam, v. 116, n. 1-2, p. 75-85, 2010.

NÓBREGA, M. B. M.; OLÍVIO, G. I.; CARVALHO, A. D. F. Avaliação de cultivares de mamona em cruzamentos dialélicos parciais. Bragantia, Campinas, v. 69, n. 2, p. 281-288, 2010.

PAINI, J. N.; CRUZ, C. D.; DELBONI, J. S.; SCAPIM, C. A. Capacidade combinatória e heterose em cruzamentos intervarietais de milho avaliados sob as condições climáticas da região sul do Brasil. Revista Ceres, Viçosa, v. 43, n. 247, p. 288-300, 1996.

RAMAlHO, M. A. P.; SANTOS, J. B.; PINTO, C. A. B. P. Genética na Agropecuária. 4. ed. Lavras: UFLA, 2008. 460 p.

SALEEM, M. Y.; MIRZA, J. I.; HAQ, M. A. Combining ability analysis for yield and related Traits in basmati rice (Oryza sativa 1.). Pakistan Journal of Botany, Faisalabad, v. 42, n. 1, p. 627-637, 2010.
SILVA, S. A. G. e; MORAIS, O. P. de; RAVA, C. A.; COSTA, J. G. C. da. Método Generalizado de análise de dialelos desbalanceados. Revista Pesquisa Agropecuária Brasileira, Brasília, v. 35, n. 10, p. 1999-2005, 2000.

SOUZA, C. A.; COELHO, C. M. M.; AMARANTE, C. V. T.; MIQUELLUTI, D. J.; VIEIRA, S. P.; ARCARO, T. F. Proposta para modificar a arquitetura de plantas de feijão pelo uso de ácido giberélico. Revista Científica Internacional Inter Science Place, Campos dos Goytacazes, v. 9, n. 12, p. 1-14, 2009.

VEIGA, R. D.; FERREIRA, D. F.; RAMALHO, M. A. P. Eficiência dos dialelos circulantes na escolha de genitores. Revista Pesquisa Agropecuária Brasileira, Brasília, v. 35, n. 7, p. 1395-1406, 2000.

VENCOVSKY, R.; BARRIGA, P. Genética biométrica no fitomelhoramento. Ribeirão Preto: Sociedade Brasileira de Genética, 1992. 486 p.

VIEIRA, C. O feijoeiro comum: cultura, doenças e melhoramento. Viçosa: UFV, 1967. 220 p.

WANDER, A. E. Introdução e importância econômica. In: COBUCCI, T.; BIAVA, M. Cultivo do feijão irrigado na Região Noroeste de Minas Gerais. Santo Antônio de Goiás: Embrapa Arroz e Feijão. 2005. (Sistemas de Produção, 5).

WU, X.; WANG, Z.; CHANG, X.; JING, R. Genetic dissection of the developmental behaviours of plant height in wheat under diverse water regimes. Journal of Experimental Botany, Oxford, v. 61, n. 11, p. 2923-2937, 2010.

ZANATTA, A. C. A.; OERLECKE, D. Efeito de genes de nanismo sobre alguns caracteres agronômicos e morfológicos de Triticum aestivum (L.) Thell. Pesquisa Agropecuária Brasileira, Brasília, v. 26, n. 7, p. 10011016, 1991.

ZHANG, K.; KANG, M. S.; LAMKEY, K. R. DiallelSas05: a comprehensive program for Griffing's and Gardner-Eberhart analyses. Agronomy Journal, Madison, v. 97, n. 8, p. 1097-1106, 2005. 
